University of Nebraska - Lincoln

DigitalCommons@University of Nebraska - Lincoln

Faculty Publications, Department of Psychology

Psychology, Department of

2010

\title{
Are All Perpetrators Alike? Comparing Risk Factors for Sexual Coercion and Aggression
}

\author{
Sarah DeGue \\ United States Centers for Disease Control and Prevention, sdegue@cdc.gov \\ David K. DiLillo \\ University of Nebraska-Lincoln, ddilillo@unl.edu \\ Mario J. Scalora \\ University of Nebraska-Lincoln, mscalora1@unl.edu
}

Follow this and additional works at: https://digitalcommons.unl.edu/psychfacpub

Part of the Psychiatry and Psychology Commons

DeGue, Sarah; DiLillo, David K.; and Scalora, Mario J., "Are All Perpetrators Alike? Comparing Risk Factors for Sexual Coercion and Aggression" (2010). Faculty Publications, Department of Psychology. 558.

https://digitalcommons.unl.edu/psychfacpub/558

This Article is brought to you for free and open access by the Psychology, Department of at DigitalCommons@University of Nebraska - Lincoln. It has been accepted for inclusion in Faculty Publications, Department of Psychology by an authorized administrator of DigitalCommons@University of Nebraska - Lincoln. 
Are All Perpetrators Alike? Comparing Risk Factors for Sexual Coercion and Aggression
Sexual Abuse: A Journal of Research and Treatmen 22(4) 402-426

(C) Public Safety Canada 2010

Reprints and permission: http://www. sagepub.com/journalsPermissions.nav DOI: I0.I I 77/I0790632I0372| 40 http://sajrt.sagepub.com

@SAGE

\author{
Sarah DeGue', David DiLillo', and \\ Mario Scalora'
}

\begin{abstract}
The present study developed and contrasted predictive models of male nonphysical sexual coercion (e.g., verbal pressure or manipulation) and physical sexual aggression (e.g., incapacitation, physical force, or threats) using a sample of 369 incarcerated males to identify shared and unique risk factors for each form of sexual perpetration. Results revealed a set of shared risk characteristics that predisposed individuals to both sexual coercion and aggression (i.e., belief in rape myths, sexual promiscuity, aggressive tendencies, and empathic deficits). In addition, findings indicated that whether the offenders engaged in only sexual coercion or also used more violent sexually aggressive tactics depended on the presence of two sets of traits unique to these forms of perpetration. Specifically, sexual coercers tended to possess traits that facilitated the use of verbal tactics (i.e., ability to manipulate others and to imagine others' emotional reactions). In contrast, sexual aggressors had characteristics that could increase their willingness to "cross the line" and resort to more violent means to obtain sex from an unwilling partner (i.e., hostility toward women, egocentricity, an impulsive disregard for sociolegal proscriptions, and childhood emotional abuse). A model of general sexual perpetration that directly contrasted sexually coercive and aggressive men was also developed, and hostility toward women was identified as the only predictor capable of predicting perpetrator group membership. Together, these findings suggest that although sexual coercers and aggressors share some underlying risk factors, the etiological patterns of these behaviors are distinct and necessitate individual attention by researchers and prevention programs.
\end{abstract}

'University of Nebraska-Lincoln, Lincoln, NE, USA

Corresponding Author:

Sarah DeGue, Division of Violence Prevention, Centers for Disease Control and Prevention, 4770 Buford Highway NE, MS-F64,Atlanta, GA 3034I, USA

Email:sdegue@cdc.gov 


\section{Keywords}

sexual coercion, sexual aggression, sexual violence, perpetration, sexual offending, verbal, manipulation, nonphysical, rape

Two unique forms of male sexual perpetration - those that involve the use of physical force and those that do not-have been frequently examined in the sexual violence literature. However, these types of perpetration, and the men who use them, are not equally understood. Perpetration involving the use of physical tactics, referred to here as sexual aggression, is recognized as the most severe and harmful form of sexual violence and is usually accompanied by clear legal and social proscriptions. This type of perpetration, which encompasses acts of forcible rape, drug-facilitated rape, and incapacitated rape (Kilpatrick, Resnick, Ruggiero, Conoscenti, \& McCauley, 2007), would typically meet criteria for a violent sexual offense. Not surprisingly, most research in the field of sexual violence has focused on these most serious offenses. Pioneering work in this area has pointed to the high prevalence of these offenses, identified important risk factors for perpetrators, and brought to light the serious shortand long-term consequences for victims (Campbell \& Wasco, 2005; Koss, 2005).

In contrast, the use of nonphysical tactics to obtain unwanted sex, referred to here (and elsewhere; Calhoun, Bernat, Clum, \& Frame, 1997; Craig, Kalichman, \& Follingstad, 1989; Koss, Leonard, Beezley, \& Oros, 1985; Lisak \& Ivan, 1995; Livingston, Buddie, Testa, \& VanZile-Tamsen, 2004) as sexual coercion, has received significantly less attention from researchers. Nonphysical tactics such as continual arguments or verbal pressure, threats to end the relationship, deceit, emotional manipulation, ignoring requests to stop without physical force, and intentional intoxication to reduce inhibitions have been routinely included in popular self-report measures of sexual violence (e.g., the Sexual Experiences Survey; Koss \& Oros, 1982). Perhaps because these tactics, often taking the form of predatory dating behaviors, represent a less severe, and legal, form of sexual perpetration, evidence suggests that they are used significantly more often than are physical tactics (e.g., Byers \& Eno, 1991; Koss et al., 1985; Lyndon, White, \& Kadlec, 2007).

\section{Prevalence and Correlates of Sexual Coercion}

Despite being commonly assessed, relatively few studies have specifically examined, in isolation, the prevalence and correlates of nonphysical tactics for obtaining unwanted sex. Surveys of college men have pointed to high rates of sexual coercion. For instance, $22.4 \%$ reported using "extreme verbal pressure" (Koss et al., 1985), 37\% to 69\% admitted using tactics of "verbal manipulation" (Byers \& Eno, 1991; Mosher \& Anderson, 1986, respectively), and $32.4 \%$ indicated they had engaged in "emotional manipulation and deceit" (Struckman-Johnson, Struckman-Johnson, \& Anderson, 2003) to obtain sex with an unwilling partner. In two more recent studies, nearly one third of sexually active college men reported using nonphysical tactics, such as continual arguments or 
pressure, abusing authority, providing alcohol or drugs, deceit, or threatening to end the relationship, to obtain unwanted sex (DeGue \& DiLillo, 2004; Lyndon et al., 2007). The perpetration of nonphysical sexual coercion by community men occurs at similar rates, ranging from 22\% to 27\% (Calhoun et al., 1997; Senn, Desmarais, Verberg, \& Wood, 2000). Furthermore, researchers found that more than half (50.5\%) of a highrisk sample of "single women, 20-35, who drink at bars and parties" had at least one unwanted sexual experience involving the use of nonphysical tactics (Testa \& Derman, 1999, p. 551). Also, 7 out of 10 college women reported experiencing "emotional manipulation" by a male partner in an attempt to gain sexual contact (StruckmanJohnson et al., 2003). Thus, current evidence suggests that the use of manipulative tactics or predatory dating behaviors to gain unwanted sex is reported frequently by both men and women.

Although the physical and psychological consequences of sexual aggression for female victims are well established (Campbell \& Wasco, 2005), less is known about the possible impact of nonphysical sexual coercion on females. Cross-sectional findings suggest that experiencing sexual coercion is associated with negative correlates, including difficulties with self-esteem, depression, and anxiety (Testa \& Derman, 1999; Zweig, Barber, \& Eccles, 1997). However, it is possible that these characteristics predated the coercive encounters and represent risk factors for experiencing sexual coercion, rather than outcomes. Although women who experience sexual coercion report that their experiences are moderately traumatic at the time, Brown, Testa, and Messman-Moore (2009) found that women who experienced sexual coercion reported fewer lasting psychological effects overall than did victims of incapacitated or forcible rape. Nevertheless, many women who have experienced coercion report negative consequences that are "not benign," including relationship problems, negative affect, and self-blame (Livingston et al., 2004, p. 295). Furthermore, sexual coercion may increase the risk of sexually transmitted disease or unplanned pregnancy as a result of coerced intercourse.

Adams-Curtis and Forbes (2004) referred to the importance of including behaviors at even the lowest-level of severity when conceptualizing sexual perpetration:

Clearly a stolen kiss is not the equivalent of a forceful rape. However, it is important to recognize that the stolen kiss is a violation of another individual's personal and sexual autonomy. Merely because such activities are common and often dismissed as insignificant, particularly by the perpetrator, does not render them right, acceptable, or harmless. More important, such activities may serve as gateways to further, and more serious, coercion. (p. 99)

Indeed, as suggested by these authors and others (e.g., DeGue \& DiLillo, 2005; Lyndon et al., 2007; Testa \& Derman, 1999), the possibility that sexual coercion may serve as a "stepping stone" to more severe sexually aggressive acts suggests a compelling need to better understand this type of perpetration. If, in fact, males who engage in lower levels of sexual perpetration are at a higher risk for progressing to 
more severe and potentially damaging forms of sexual aggression, then a better understanding of these initial behaviors may shed light on potential targets for interventions aimed at interrupting this escalation.

\section{Risk Factors for Sexual Coercion}

To date, research has tended to collapse sexual coercion and aggression into one category when examining risk factors (e.g., Aberle \& Littlefield, 2001; Bernat, Calhoun, \& Adams, 1999; Rapaport \& Burkhart, 1984; Senn et al., 2000). However, a few studies have specifically explored risk factors associated with sexual coercion, primarily through comparisons with consensual-only men. These studies reveal that sexually coercive men evidence increased sexually permissive attitudes, greater acceptance of attitudes toward rape, and increased college fraternity membership, alcohol consumption, and promiscuity (Craig et al., 1989; Koss et al., 1985; Tyler, Hoyt, \& Whitbeck, 1998). Furthermore, DeGue and DiLillo (2004) found that sexually coercive college men, compared with nonperpetrators, were more likely to subscribe to rape myths, view interpersonal violence as acceptable, endorse hostility toward females, and perceive male-female relationships as inherently adversarial. Sexually coercive males also reported more promiscuity, indicators of delinquency, psychopathic personality traits, empathic deficits, child physical and psychological abuse, and exposure to parental violence than their noncoercive peers.

Only two studies appear to have directly compared risk factors associated with nonphysical sexual coercion and physical sexual aggression. DeGue and DiLillo (2004) found that sexually aggressive college men endorsed a stronger belief in rape myths than coercive men. However, these perpetrator groups did not differ from one another on any other risk factors assessed, including negative attitudes toward women, general aggression, promiscuity, rape proclivity, delinquency, psychopathic traits, empathy, and child maltreatment history. Though based on only a small comparison sample of self-identified sexual aggressors $(n=18)$, these findings hint at important parallels between these seemingly disparate forms of sexual violence. In a second study, also with a college sample, Lyndon et al. (2007) contrasted male perpetrators who had used manipulation (i.e., sexual coercers) with those who used force (i.e., sexual aggressors). Results indicated that coercive and aggressive men did not differ from each other on measures of child physical abuse, delinquency, and domination/hedonism motives for sex. However, on measures of child sexual abuse, witnessing domestic violence, and acceptance of male violence, sexually coercive men again endorsed these characteristics less strongly than sexual aggressors (but scored higher than consensual-only men). Interestingly, sexually coercive men reported less endorsement of traditional gender role beliefs than either consensual-only or sexually aggressive men. Thus, consistent with DeGue and DiLillo (2004), coercive and aggressive groups in this study both reported higher levels of most risk factors than consensual-only men. However, Lyndon et al., using a slightly larger $(n=39)$ comparison sample of sexually aggressive college men, did identify between-group differences on some previously examined 
variables (e.g., sexual abuse, witnessing parental violence, acceptance of male violence). Overall, these authors concluded that sexually coercive and aggressive men "constitute meaningfully different groups," supporting the need for further research addressing each form of perpetration as separate behavioral categories (p. 299). The use of larger comparison groups could provide additional insight regarding the ability of such risk factors to differentiate between coercive and aggressive perpetrators.

\section{The Present Study: Contrasting Models of Sexual Coercion and Aggression}

Past research highlights a set of risk factors that may differentiate sexually coercive and aggressive men from nonperpetrators and each other. However, these studies have usually examined only a subset of potential risk factors or have used small comparison groups. The present study expands on past research by providing a direct comparison of sexually coercive and aggressive men using a more comprehensive set of theoretically relevant predictors. In doing so, we have considered current theoretical models of sexual offending that suggest the importance of risk factors from multiple domains in the etiology of sexual perpetration (e.g., Knight \& Sims-Knight, 2009; Malamuth, Sockloskie, Koss, \& Tanaka, 1991). Among the most widely studied models of this type, Malamuth's confluence model identifies two paths to sexual aggression leading from childhood maltreatment through delinquency and either attitudes supporting violence and hostile masculinity, or sexual promiscuity (Malamuth et al., 1991). This model has been empirically supported (e.g., Malamuth, Linz, Heavey, Barnes, \& Acker, 1995) and is useful in identifying risk factors from several key domains, including childhood experiences, personality characteristics, attitudes and beliefs, and past behavior.

Consistent with Malamuth's well-established model, the current study included the same four classes of variables in an effort to distinguish between men who engage in sexual coercion only and those who also perpetrate more severe acts of sexual aggression. In the attitudinal domain, we assess: belief in rape myths (e.g., Byers \& Eno, 1991; Muehlenhard \& Falcon, 1990; Tyler et al., 1998) and hostility toward women (e.g., Koss \& Dinero, 1988; Lisak \& Roth, 1988; Malamuth, Heavey, \& Linz, 1993). In the behavioral realm, generalized aggressive tendencies and sexual promiscuity are included based on prior linkages to sexual aggression (e.g., Abbey, McAuslan, Zawacki, Clinton, \& Buck, 2001; Calhoun et al., 1997; Hersh \& Gray-Little, 1998; Malamuth et al., 1991). Dispositional characteristics, including deficits in empathic abilities and psychopathic personality traits are also examined because of their consistent connection to sexual offending (e.g., Fernandez \& Marshall, 2003; Kosson \& Kelly, 1997; Lindsey, Carlozzi, \& Eells, 2001; Lisak \& Ivan, 1995; Senn et al., 2000). Finally, past trauma exposure in the form of childhood abuse and neglect has also been linked to sexual aggression and, thus, was included in the present study as well (e.g., Dhawan \& Marshall, 1996; Malamuth et al., 1991; Simons, Wurtele, \& Heil, 2002).

In contrast to past research with college males, the current study uses a sample of incarcerated men. We expected this population to yield a larger comparison sample of 
sexual aggressors to aid in making between-group comparisons. Moreover, inmates are likely to possess higher levels of several established risk factors for sexual aggression (e.g., general aggression, child abuse history, psychopathic personality traits, delinquency), which also facilitates the specification of multivariate predictive models. Finally, the use of an older, more sexually experienced sample reduces the likelihood that we are assessing participants while their patterns of sexual behavior are still in an early phase of development.

Consistent with the confluence model of sexual aggression (Malamuth et al., 1991), which suggests a complex, multidimensional etiology of sexual violence, we hypothesized multifactor models of sexual coercion and aggression that include risk characteristics from various areas of functioning. Each of the factors included here has also been supported in past empirical literature. However, by examining the relative contributions of specific characteristics within the categories of attitudes, behavior, personality traits, and child maltreatment history, we also expected to identify factors that were uniquely important for perpetration of sexual coercion or aggression.

\section{Method}

\section{Participants}

Participants were 360 recently adjudicated adult males recruited from a state correctional facility. The mean age of participants was 32.1 years $(S D=10.2)$ with a range of 19 to 67 years. The majority of participants were Caucasian (65.6\%), though other ethnic groups were represented in the sample (African American, 16.9\%; Hispanic/ Latino, 8.1\%; Native American, 3.1\%; Multiracial, 6.4\%). Unmarried participants composed the largest group in the sample (45.8\%), followed by divorced (18.1\%) and married (16.4\%) men. Most of the study participants completed their highest level of education in Grades 9 to 11 (44.2\%), completed Grade 12 (21.4\%), or had some college $(26.1 \%)$.

The mean number of criminal convictions for this sample, including the index offense(s), was 14.0 (median $=11)$. Almost all participants $(95 \%)$ had been convicted of at least one nonviolent offense (e.g., drug offense, theft) at some point in the past. More than half of participants (51.9\%) had been convicted of at least one violent, nonsexual offense (e.g., homicide, assault). Sexual offenses (e.g., sexual assault of an adult or child) were less common, with less than a quarter of the sample (23.1\%) convicted of an offense in this category. After the age of 18 years, participants selfreported being incarcerated an average of 38.4 months (median $=15)$.

\section{Measures}

\section{Attitudinal or Belief Systems}

RAPE scale. The 36-item RAPE scale (Bumby, 1996; 1 = strongly agree, 4 = strongly disagree) assesses cognitive distortions associated with sexual offending. This measure 
incorporates more current language to assess concepts similar to Burt's (1980) scale on rape myth acceptance. Internal consistency of the RAPE scale, as reported by Bumby, was excellent with a standardized alpha coefficient of .96. The test-retest correlation was .86 over a 2-week interval. Cronbach's alpha in the present sample was .94.

Hostility Toward Women Scale. The Hostility Toward Women Scale (HTW; Check, Malamuth, Elias, \& Barton, 1985) includes 30 items assessing angry and distrustful attitudes toward females in a true-false format (e.g., "It is safer not to trust women"). Check et al. (1985) reported acceptable reliability and validity for the HTW, which has been shown to correlate significantly with a history of sexual aggression. In addition, a coefficient alpha of .81 indicated high internal consistency for this scale in the present sample.

\section{Behavioral Tendencies}

Aggression Questionnaire. The Aggression Questionnaire (AQ; Buss \& Perry, 1992) assesses overall aggression in males and females, as well as four specific components of aggression (e.g., physical aggression, verbal aggression, anger, and hostility; $1=$ extremely characteristic of me, $5=$ extremely uncharacteristic of me). Only the total scale score was included in the present study. This measure is reported to have adequate internal consistency and test-retest reliability (Buss \& Perry, 1992). In the present sample, internal consistency was excellent with a coefficient alpha of .93.

Promiscuity indicators. Sexual promiscuity was assessed with two open-ended items assessing: age of first sexual intercourse and number of sexual intercourse partners since the age of 14 years (see Malamuth et al., 1991). Participants were also asked to report the number of their sexual partners since age 14, if any, who had forced them to engage in sexual acts against their will (i.e., participants' rape or child sexual abuse experiences). These perpetrators were subtracted from the total number of sexual partners reported to more accurately reflect participants' voluntary sexual behavior.

\section{Personality Factors}

Interpersonal Reactivity Index. The 28-item Interpersonal Reactivity Index (IRI; Davis, $1980 ; 1$ = strongly agree, 5 = strongly disagree) includes four subscales measuring different dimensions of empathy: Perspective Taking (adopting the perspective of others), Fantasy (identifying with the emotions of fictitious characters in movies, books, etc.), Empathic Concern (feelings of sympathy for others), and Personal Distress (feelings of discomfort in response to the distress of others). Davis (1980) reported evidence of concurrent validity, as well-acceptable test-retest reliability coefficients (ranging from .61 to .81) and internal consistency for each subscale (ranging from .71 to .77). Consistent with recommendations by Pulos, Elison, and Lennon (2004), the Personal Distress subscale was excluded from the present study. Coefficients alphas for the remaining subscales (i.e., Perspective Taking, Empathic Concern, and Fantasy) ranged from .67 to $.70(M=.69)$.

Psychopathic Personality Inventory-Short Form. The Psychopathic Personality InventoryShort Form (PPI-SF; Lilienfeld, 1990) is a 56-item inventory $(1=$ false, $2=$ mostly 
false, $3=$ mostly true, $4=$ true), which assesses the presence of psychopathic personality traits across eight factor-analytically derived dimensions (i.e., Machiavellian Egocentricity, Social Potency, Coldheartedness, Carefree Nonplanfulness, Fearlessness, Blame Externalization, Impulsive Nonconformity, and Stress Immunity). Lilienfeld and Andrews (1996) reported moderate to high correlations between this self-report measure of psychopathic traits and other measures of psychopathy and antisocial personality disorder, including the Psychopathy Checklist-Revised (PCL-R; Hare, 1991). The PPI-SF has been found to correlate $(r=.90)$ with the PPI full form, with a reported internal consistency of .85 overall and a range of .64 to .85 for the subscales. Reliability analyses for the present sample indicated that the removal of two items (Items 53 and 54) from the PPI significantly improved the overall internal consistency. With these items removed, the alpha coefficient for the total scale score improved from .68 to .70. Removal of one item each from the Coldheartedness and the Impulsive Nonconformity subscales resulted in improved alpha coefficients from .64 to .65 and .58 to .68 , respectively. Internal consistency for the remaining full subscales ranged from .65 to $.75(M$ of all subscales $=.69)$. Subscale scores for each of the eight dimensions were used in the present study.

\section{Childhood Abuse Experiences}

Childhood Trauma Questionnaire. The Childhood Trauma Questionnaire (CTQ; Fink, Bernstein, Handelsman, Foote, \& Lovejoy, 1995) is a 28 -item self-report inventory $(1=$ never true, $5=$ very often true $)$, which provides a brief assessment of childhood abuse experiences, including physical, sexual, and emotional abuse, as well as physical and emotional neglect. A three-item Minimization/Denial scale was not included in analyses. Internal consistency for the four abuse scales ranged from .66 (Neglect) to .92 (Sexual), and test-retest correlations were high (.79 to .86; Fink et al., 1995). In the present sample, reliability analyses produced alpha coefficients of .86 for the total scale and a range of .68 to $.94(M=.84)$ for subscale scores. Subscale scores for each maltreatment type were used in this study.

\section{Assessment of Sexual Perpetration}

Sexual Experiences Questionnaire. A history of sexually coercive and aggressive behavior was assessed using a 12-item version $(1=$ never, $5=$ often $)$ of the Sexual Experiences Questionnaire (SEQ; Lisak \& Roth, 1988). The SEQ is a modified version of the Sexual Experiences Survey (SES; Koss \& Oros, 1982; Koss \& Gidycz, 1985), a measure of sexual behavior used extensively in past research on sexual perpetration. Both measures include items regarding the use of lies, false promises, continual arguments, threats to end the relationship, drug or alcohol impairment, and threats or use of physical force to obtain sexual contact. An additional item was added to assess a lower level tactic involving the use of alcohol or drugs that has not previously been included in these measures (i.e., "Have you ever obtained sexual intercourse with a woman by deliberately giving her alcohol or drugs to impair her judgment?"). An internal consistency reliability coefficient of .89 for college men and a 1-week test-retest 
reliability with a mean item agreement of $93 \%$ was reported by Koss and Gidycz (1985) for the SES. Lisak and Roth (1988) conducted a small-scale assessment of validity for the SEQ using post-test interviews and reported "a greater degree of validity . . . than was earlier reported" for the SES.

Sexual coercers were identified based on their responses to the SEQ, and included any individuals who reported using of one or more nonphysical tactics to obtain sexual intercourse (i.e., threatening to end the relationship, continual arguments, lies, providing intoxicants to impair her judgment, persisting without physical force). Sexual aggressors, in contrast, were identified through one of two means: (a) Participants with criminal records indicating a past sexual assault conviction (involving an adult female) were considered sexual aggressors and (b) Given that official conviction rates vastly underestimate the prevalence of sexual aggression (e.g., Koss, Gidycz, \& Wisniewski, 1987), sexual aggressors were also identified by their self-reported behavior on the SEQ. Self-reported sexual aggression included sexual contact (fondling or intercourse) obtained through the threat or use of physical force, attempted physical force, or secondary to getting a woman too drunk or high to physically resist. Participants were classified based on their highest level of sexual offending. That is, those participants who engaged in both sexually coercive and aggressive behaviors were considered sexual aggressors for the purposes of this study.

\section{Procedure}

Participants were recruited from a Midwestern state correctional facility. All inmates at this facility were entering the correctional system following a recent criminal conviction to undergo medical and psychological evaluations before being transferred to another facility. Recruitment signs were placed throughout the facility inviting inmates to participate in a research project concerned with "life experiences and sexual behavior." All male inmates were eligible to participate regardless of their convicted offense. Data collection took place in small groups ( $<10$ participants $)$ facilitated by a graduate student and a trained research assistant. Interested inmates were presented with an informed consent form, which was read aloud by the investigator at the start of the session. Confidentiality of participant responses, especially with regard to prison officials, was emphasized by the investigator during this procedure. Every participant was informed that the responses would be confidential and that their participation would not affect their relationship with the criminal justice system. No prison officials were present in the room during data collection. Participants were given an opportunity to ask questions about the content of the informed consent form and to withdraw from the study without any penalty. Participants were not asked to provide their name or other identifying information on study materials. All materials were identified by a participant number only. Participants were asked to place their completed measures in an unmarked envelope and to put the envelope inside a slotted box to ensure the confidentiality of their data. With participants' consent, criminal history information was coded based on available medical records, police reports, and court documents in 
institutional files. Participants were compensated on completion of the study with a payment of $\$ 10.00$ directly deposited into their institutional account. This study was approved by institutional review boards at the University of Nebraska-Lincoln and the state correctional agency.

\section{Results}

\section{Prevalence of Sexual Coercion and Aggression}

The majority of participants were classified as either sexually coercive (51.4\%) or sexually aggressive (19.7\%) based on the most severe form of sexual perpetration self-reported on the SEQ or indicated in criminal history information obtained from institutional files. Approximately one third (33.5\%) of coercers and three fourths (76\%) of aggressors endorsed the use of two or more tactics for obtaining unwanted sexual contact on the SEQ. Although $63.4 \%$ of sexually aggressive men were classified based on their self-reported behavior on the SEQ alone, another 31\% were classified on the basis of criminal history information indicating a prior sexual offense conviction involving an adult female, or on the agreement of both sources $(5.6 \%)$. Notably, $90.1 \%$ of sexually aggressive men also reported engaging in lower level sexually coercive behaviors. Of those few sexual aggressors who denied the use of nonphysical, coercive tactics on the SEQ, most $(85.7 \%)$ had been classified as aggressive based on their criminal records. Only one participant (14.3\% of the aggression-only men) self-reported sexually aggressive behavior on the SEQ, but denied using coercive tactics. Thus, it is important to note that, with few exceptions, men in both groups of perpetrators had engaged in sexually coercive behavior, with the primary behavioral difference between the groups being the additional reports of physical force in the sexually aggressive sample. Of the full sample, $28.9 \%$ had no self-reported or criminal history of sexual perpetration and were classified as having "consensualonly" sexual relationships.

\section{Data Analysis Strategy for Model Development}

The primary goals of the present study were to identify unique risk factors for sexual coercion and aggression and to examine the relative contributions of these risk factors within each perpetrator group. Consistent with these objectives, binary logistic regression analysis was used to develop three multifactor predictive models with the following dichotomous criterion variables: sexual coercion (sexual coercers vs. consensual-only), sexual aggression (sexual aggressors vs. consensual-only), and sexual perpetration (sexual coercion vs. sexual aggression). Final models were constructed in two stages. First, to assess the relative importance of predictors within each category of variables, separate logistic regressions were run for each set of predictor variables (i.e., attitudinal and belief factors, behavioral tendencies, personality factors, and child abuse experiences). Based on these results, significant 
predictors within each variable category (when controlling for other variables of the same type) were identified. In the second stage, this reduced set of predictors was entered into final logistic regression models to predict sexual coercion, sexual aggression, or to discriminate between sexual coercers and aggressors in the sexual perpetration model. This second step revealed the relative importance of risk variables across categories of predictors. Our intent was to identify and contrast risk factors for each type of perpetration. This two-step approach provided a richer and more descriptive etiological picture of these individual forms of sexual perpetration than would a one-step multinomial approach. Two variables, education level and child molestation conviction, were also included in the final models as covariates due to their differential rates across offender groups in bivariate analyses. Cases with missing data are automatically excluded from logistic regression analyses. Thus, in some analyses, the number of cases was lower than the total sample for that category of the criterion.

Group means for all measures are presented in Table 1. Follow-up bivariate analyses revealed that sexual aggressors scored worse (e.g., endorsing more of a negative characteristic) than coercers, and sexual coercers worse than consensual-only men, on belief in rape myths, hostility toward women, and generalized aggression. In contrast, the sexually coercive and aggressive groups both scored significantly worse than consensual-only men, though not differently from each other, on the promiscuity indicators, empathic concern, egocentricity, carefree nonplanfulness, fearlessness, and impulsive nonconformity. Sexual coercers also scored worse than consensual-only men on the social potency component of psychopathy, but better than this group on the fantasy subscale of the empathy measure. Finally, sexual aggressors endorsed more emotional abuse than coercive or consensual-only men, more physical abuse and sexual abuse than sexual coercers, and more blame externalization and physical neglect than the consensual-only group.

Intercorrelations between predictor variables are presented in Table 2. To assess for multicollinearity, variance inflation factors (VIFs) were calculated for each variable included in the models. Results indicated that VIFs for each of the independent variables were well below the standard cutoff of 10, and all but two factors (Emotional Abuse $=3.7$; Physical Abuse $=3.2$ ) were below the most conservative cutoff typically used of 2.5, thus minimizing concerns about the potential impact of multicollinearity on the results (Allison, 1999). Results from the first level of within-category analyses for each criterion set are presented in Table 3 . As noted above, only those variables that were significant predictors in these analyses were included in the final models presented below and in Table 4.

\section{Model Predicting Sexual Coercion}

A logistic regression model with six predictors (belief in rape myths, generalized aggression, number of sexual partners, IRI fantasy, IRI empathic concern, PPI social potency) and two covariates (child molestation history, educational level) was 
Table I. Descriptive Statistics for Predictor Variables by Sexual Perpetration Status

\begin{tabular}{|c|c|c|c|c|}
\hline \multirow[b]{2}{*}{ Predictor Variables } & \multicolumn{3}{|c|}{$M(S D)$} & \multirow[b]{2}{*}{$F$} \\
\hline & $\begin{array}{l}\text { Consensual-Only } \\
\quad(n=104)\end{array}$ & $\begin{array}{l}\text { Coercers } \\
(n=185)\end{array}$ & $\begin{array}{l}\text { Aggressors } \\
(n=7 I)\end{array}$ & \\
\hline Belief in Rape Myths ${ }^{a}$ & II $9.3(16.4)^{\mathrm{b}}$ & II3.0 (14.4) & $107.5(18.0)^{b}$ & $12.3 * *$ \\
\hline $\begin{array}{l}\text { Hostility Toward } \\
\text { Women }\end{array}$ & $8.4(5.1)^{b}$ & $10.1(5.1)^{b}$ & $12.7(5.3)^{\mathrm{b}}$ & $14.5^{* *}$ \\
\hline $\begin{array}{l}\text { Generalized } \\
\text { Aggression }^{\mathrm{a}}\end{array}$ & I $25.0(28.8)^{b}$ & II $4.2(27.1)^{b}$ & $104.2(30.2)^{b}$ & $11.8^{*}$ \\
\hline $\begin{array}{l}\text { Age of first sexual } \\
\text { intercourse }\end{array}$ & I $4.7(3.4)^{\mathrm{b}, \mathrm{c}}$ & $13.8(2.8)^{b}$ & $13.6(3.0)^{c}$ & $4.3^{* *}$ \\
\hline $\begin{array}{l}\text { Total number sexual } \\
\text { partners }\end{array}$ & $21.9(31.6)^{b, c}$ & $32.4(38.9)^{\mathrm{b}}$ & $41.6(49.5)^{c}$ & $5.3^{* *}$ \\
\hline IRI Perspective Taking & $10.9(4.7)$ & II 1.8 (4.9) & I $2.2(5.1)$ & 1.9 \\
\hline IRI Fantasy & I4.9 (5.6) & $13.1(5.2)^{b}$ & I $3.4(5.3)$ & $3.7^{*}$ \\
\hline IRI Empathic Concern & $8.2(4.5)^{b, c}$ & $9.6(4.5)^{b}$ & $10.1(5.3)^{c}$ & $4.4^{*}$ \\
\hline $\begin{array}{l}\text { PPI Machiavellian } \\
\text { Egocentricity }\end{array}$ & I $3.5(4.4)^{\mathrm{b}, \mathrm{c}}$ & $15.5(3.8)^{b}$ & $16.5(4.1)^{c}$ & $12.8^{* *}$ \\
\hline PPI Social Potency & I8.8 $(4.0)^{\mathrm{b}}$ & $19.9(3.9)^{b}$ & $19.3(4.1)$ & 2.6 \\
\hline PPI Coldheartedness & $11.9(3.6)$ & $12.1(3.2)$ & $12.2(3.6)$ & 0.2 \\
\hline $\begin{array}{l}\text { PPI Carefree } \\
\text { Nonplanfulness }\end{array}$ & $12.9(3.6)^{b, c}$ & $13.8(3.4)^{b}$ & $14.6(3.7)^{c}$ & 5.0 *** \\
\hline PPI Fearlessness & $18.3(4.7)^{\mathrm{b}, \mathrm{c}}$ & $19.6(4.3)^{b}$ & $18.7(5.0)^{c}$ & 2.8 \\
\hline $\begin{array}{l}\text { PPI Blame } \\
\text { Externalization }\end{array}$ & $16.6(5.1)^{b}$ & $16.9(4.3)$ & $18.1(5.2)^{b}$ & 2.4 \\
\hline $\begin{array}{l}\text { PPI Impulsive } \\
\text { Nonconformity }\end{array}$ & II.4 (3.8) $)^{\mathrm{b}, \mathrm{c}}$ & $13.1(3.5)^{b}$ & $13.2(3.8)^{c}$ & $8.0 * *$ \\
\hline PPI Stress Immunity & $21.0(4.1)$ & $20.7(3.7)$ & $19.9(4.0)$ & 1.8 \\
\hline Emotional Abuse & $5.3(5.9)^{\mathrm{b}}$ & $5.5(5.5)^{c}$ & $6.2(6.1)^{b, c}$ & $4.0^{*}$ \\
\hline Physical Abuse & $6.4(6.4)$ & $6.2(6.1)^{b}$ & $7.3(5.9)^{\mathrm{b}}$ & 0.8 \\
\hline Sexual Abuse & $3.0(6.0)$ & $2.5(5.2)^{b}$ & $4.5(6.6)^{b}$ & $3.2^{*}$ \\
\hline Emotional Neglect & $6.0(6.0)$ & $6.5(5.3)$ & $7.0(5.5)$ & 0.7 \\
\hline Physical Neglect & $3.1(3.8)^{b}$ & $3.9(4.0)$ & $4.6(4.3)^{b}$ & 2.8 \\
\hline
\end{tabular}

Note. IRI = Interpersonal Reactivity Index; PPI = Psychopathic Personality Inventory. Means in a row sharing superscripts ( $b$ and $c$ ) differ significantly at $p<.05$.

a. Lower scores indicate more endorsement of the attribute assessed.

$* p<.05 . * * p<.01$.

constructed. Results of the analyses indicated that the final model was statistically reliable, $\chi^{2}(8, N=271)=46.6, p<.01$, and that the predictors, as a set, reliably distinguished sexually coercive from consensual-only men. The model accounted for over one-fifth of the variance in sexual coercion (Nagelkerke's $R^{2}=.22$ ), producing an overall correct classification rate of $73.1 \%$. As shown in Table 1, five of the six variables significantly predicted sexual coercion: Belief in rape myths, number of sexual 


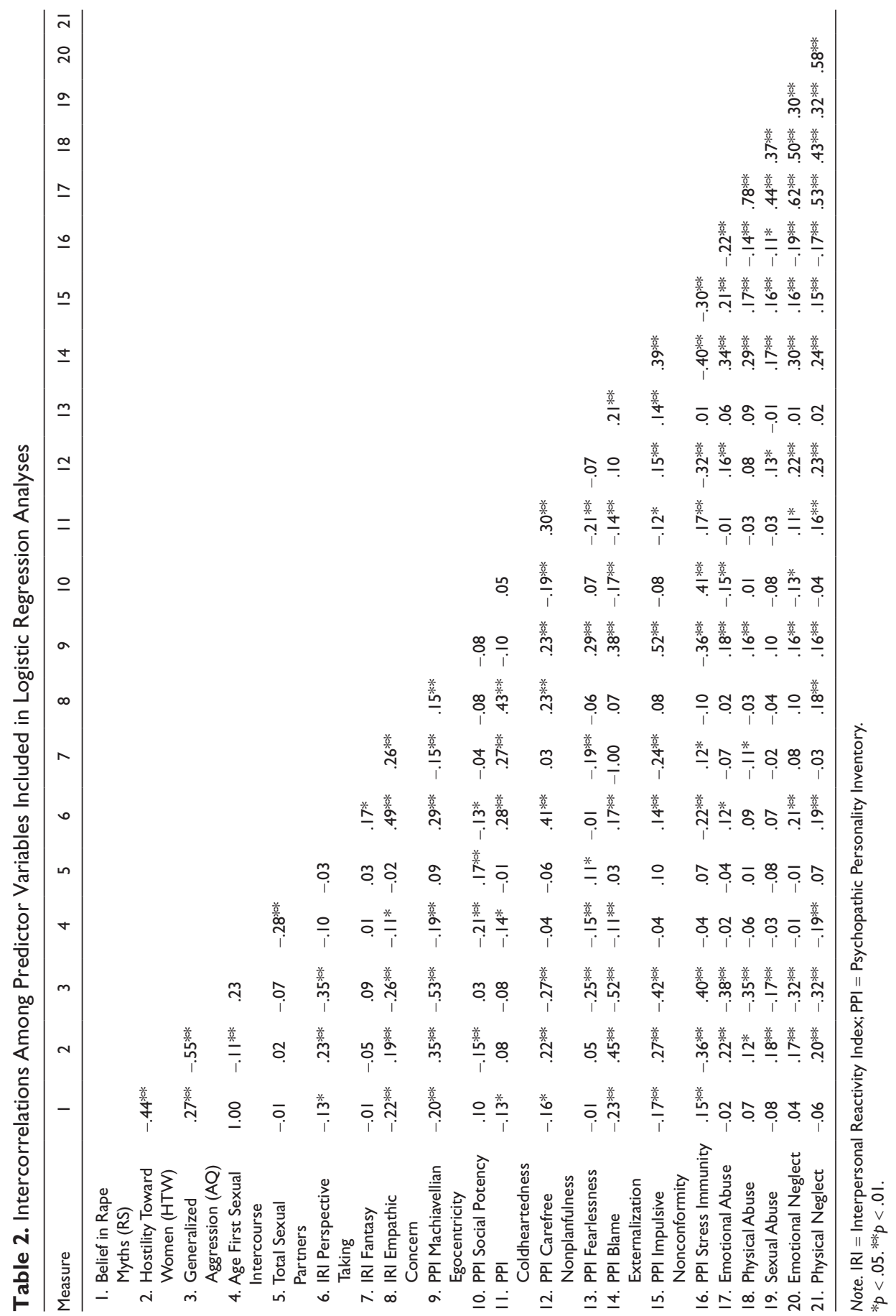




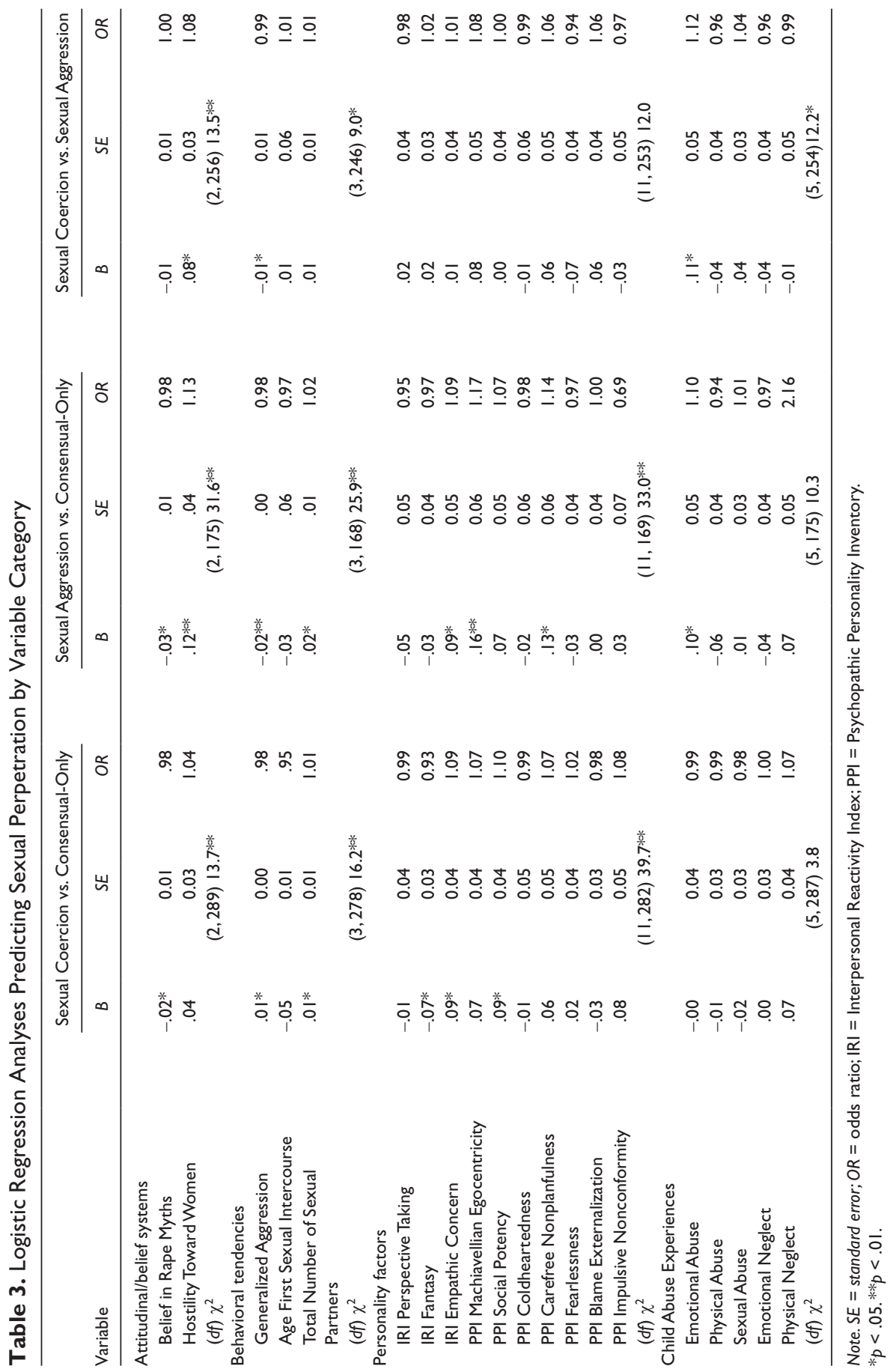


Table 4. Final Models Predicting Sexual Coercion, Sexual Aggression, and Sexual Perpetration

\begin{tabular}{lrrrc}
\hline Variable & $B$ & $S E$ & $O R$ & Wald Statistic \\
\hline Sexual coercion vs. consensual-only & & & & \\
$\quad$ Belief in Rape Myths & -.03 & 0.01 & 0.97 & $7.76^{* *}$ \\
Generalized Aggression & -.01 & 0.01 & 0.99 & 1.40 \\
Number of Sexual Partners & .01 & 0.01 & 1.01 & $3.82^{*}$ \\
IRI Fantasy & -.09 & 0.03 & 0.91 & $10.57^{* *}$ \\
IRI Empathic Concern & .10 & 0.04 & 1.10 & $7.92^{* *}$ \\
PPI Social Potency & .07 & 0.04 & 1.08 & $4.13^{*}$ \\
Sexual aggression vs. consensual-only & & & & \\
Belief in Rape Myths & -.03 & 0.01 & 0.97 & $4.94^{*}$ \\
Hostility TowardWomen & .06 & 0.05 & 1.06 & 1.69 \\
Generalized Aggression & .01 & 0.01 & 1.01 & 0.05 \\
Number of Sexual Partners & .02 & 0.01 & 1.02 & $5.16^{*}$ \\
IRI Empathic Concern & .06 & 0.04 & 1.06 & 2.27 \\
PPI Machiavellian Egocentricity & .11 & 0.06 & 1.11 & 3.57 \\
PPI Carefree Nonplanfulness & .11 & 0.06 & 1.12 & $3.77^{*}$ \\
Emotional Abuse & .07 & 0.04 & 1.07 & 3.58 \\
Sexual coercion vs. sexual aggression & & & & \\
Hostility Toward Women & .08 & 0.03 & 1.09 & $6.92^{* *}$ \\
Generalized Aggression & -.00 & 0.01 & 1.00 & 0.20 \\
Emotional Abuse & .05 & 0.11 & 1.05 & 3.15 \\
\hline
\end{tabular}

Note. $S E=$ standard error; $O R=$ odds ratio; $I R I=$ Interpersonal Reactivity Index; PPI = Psychopathic Personality Inventory.

$* p<.05$. ** $p<.01$.

partners, fantasy, empathic concern, and social potency. Generalized aggression was no longer a reliable predictor of sexual coercion when variables from other categories were considered.

\section{Model Predicting Sexual Aggression}

A logistic regression model with eight predictors (belief in rape myths, hostility toward women, generalized aggression, number of sexual partners, IRI empathic concern, PPI egocentricity, PPI carefree nonplanfulness, emotional abuse) and two covariates (child molestation history, educational level) was constructed. Results of the analyses revealed that this model was statistically reliable, $\chi^{2}(10, N=162)=54.4$, $p<.01$, and distinguished sexually aggressive from consensual-only men. The model accounted for almost $40 \%$ of the variance in sexual aggression (Nagelkerke's $R^{2}=$ .39), producing an overall correct classification rate of $75.3 \%$. As shown in Table 4, three of the eight variables reliably predicted sexual aggression: belief in rape myths, number of sexual partners, and the carefree nonplanfulness component of psychopathy. 
Hostility toward women, generalized aggression, empathic concern, egocentricity, and emotional abuse were no longer reliable predictors of sexual aggression when variables from other categories were considered.

\section{Model Predicting Sexual Coercion Versus Sexual Aggression}

A logistic regression model with three predictors (hostility toward women, generalized aggression, emotional abuse) and two covariates (child molestation history, educational level) was constructed. This model was statistically reliable, $\chi^{2}(5, N=$ $252)=18.3, p<.01$, and capable of distinguishing between sexually coercive and sexually aggressive men. The model accounted for only $10 \%$ of the variance in sexual perpetration (Nagelkerke's $R^{2}=.10$ ), producing an overall correct classification rate of $72.2 \%$. As shown in Table 4, only one of the three variables reliably predicted sexual perpetration, hostility toward women. Generalized aggression and emotional abuse were no longer reliable predictors of sexual perpetration when variables from other categories were considered.

\section{Discussion}

Based on self-report and official records, more than $70 \%$ of the present sample of incarcerated males had engaged in at least one form of sexual perpetration in their lifetime. More than half (51.4\%) of the participants reported the use of sexually coercive tactics, whereas almost one in five (19.7\%) had engaged in sexual aggression. As expected, given the use of an incarcerated sample, the rates of sexual perpetration in the current study were higher than those reported in previous research with college and community samples (e.g., Calhoun et al., 1997; Koss et al., 1985). Notably, more than 90\% of sexual aggressors also reported engaging in sexually coercive behaviors, leaving few participants $(n=7)$ to be considered "aggressive-only." Given that six of the seven "aggressive-only" participants had been convicted of sexual offenses but denied any sexual perpetration on the self-report measure, it is possible that their self-report data was not reliable. Thus, the proportion of sexually aggressive men who had also used coercive tactics may be even higher than $90 \%$. This finding is highly consistent with available self-report data from college studies in which $88.9 \%$ (DeGue \& DiLillo, 2004 ) and $84.6 \%$ (Lyndon et al., 2007) of sexually aggressive men also reported nonphysical coercion. Indeed, it may be that the most common perpetrator groups include (a) men who use only nonphysical coercive behaviors and (b) men who use both nonphysical and physical tactics. The "specialist" who employs only physical tactics may be quite rare. Unfortunately, it not possible to determine from the available data whether individuals who reported both forms of perpetration engaged in these behaviors concurrently or whether, as hypothesized by some authors (e.g., DeGue \& DiLillo, 2004, 2005; Testa \& Derman, 1999), sexually coercive behavior preceded the use of higher level sexually aggressive acts. Future research on the overlap of these behaviors may illuminate patterns of sexual perpetration with implications for prevention. 


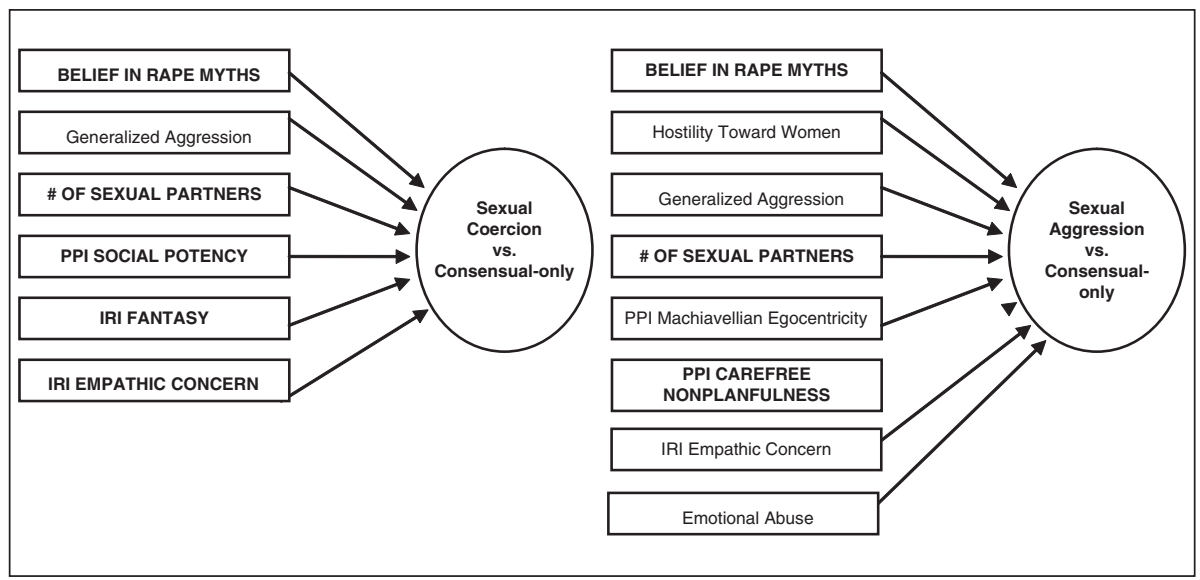

Figure I. Final models of sexual coercion and aggression

Note. Bolded, capitalized predictors were significant predictors in the final models. Other predictors were significant only in first-level, within-category analyses. IRI = Interpersonal Reactivity Index; PPI = Psychopathic Personality Inventory.

A primary objective of the present investigation was to identify shared and unique risk factors for sexual coercion and aggression by developing and contrasting comprehensive predictive models for each form of sexual perpetration. Figure 1 presents a graphical depiction of these final models and identifies the predictors that distinguished men who used sexually coercive or aggressive tactics from their consensualonly counterparts. Figure 2 presents a preliminary theoretical model of sexual perpetration in which the shared risk characteristics identified here act as predisposing factors for both coercion and aggression. When these underlying factors are combined with additional traits and experiences unique to each type of sexual perpetration, two potential pathways emerge for those individuals who engage in only lower level coercive offenses and those who also use more severe aggressive tactics to obtain sex.

Several shared risk factors were identified as important in differentiating both coercive and aggressive perpetrators from consensual-only men: belief in rape myths, promiscuity, general aggression, and empathic deficits. Given the strength of support for each of these variables in the general sexual offender literature, the role of these factors in the prediction of both sexual coercion and aggression is not surprising. Moreover, the function of each in increasing the risk for physical, nonphysical, or both forms of sexual violence is relatively clear. For example, support for belief in rape myths as a critical shared risk factor suggests that, regardless of the extent or nature of the sexual perpetration - from low-level nonphysical behaviors to forcible rape, subscribing to these myths seems to provide the perpetrator with a perception of cultural permission and justification for the use of inappropriate sexual tactics when confronted with an unwilling partner. In fact, results indicated that as belief in these myths increased, the likelihood that the perpetrator had engaged in more severe forms of 


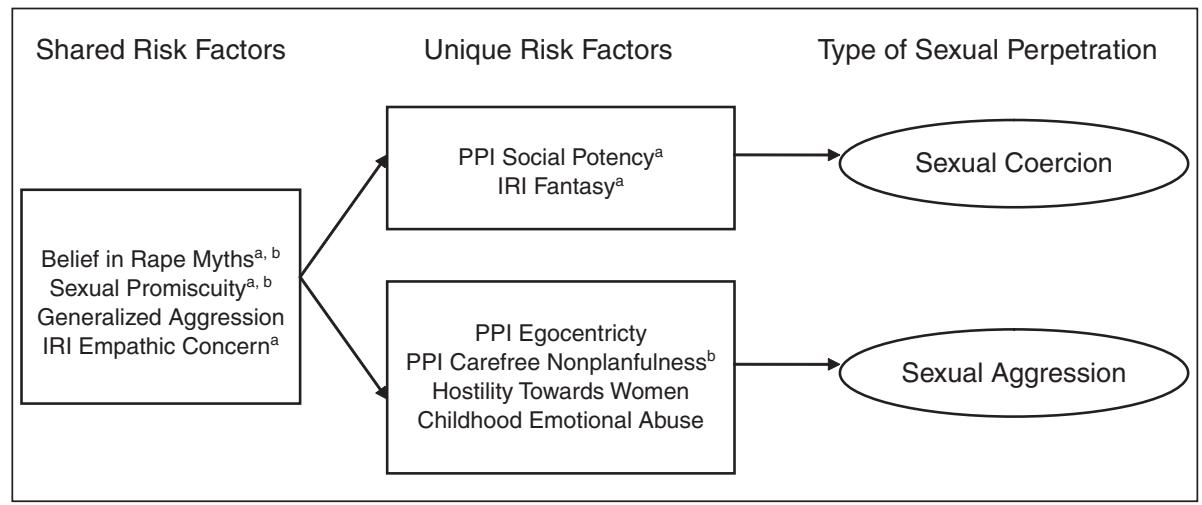

Figure 2. Theoretical model of the etiology of sexual perpetration

Note. Model includes significant predictors at the first (within categories) and second (between categories) stages of analyses. IRI = Interpersonal Reactivity Index; PPI = Psychopathic Personality Inventory.

a. Factor was significant in final sexual coercion model.

b. Factor was significant in final sexual aggression model.

sexual offending also increased. Although it is possible that promiscuity estimates were inflated for offenders because of their successful use of these tactics, it is also plausible that promiscuous behavior itself is an indicator of a casual attitude toward sexual relationships that could explain both the greater numbers of partners and the corresponding sexual perpetration. The role of generalized aggressive tendencies identified here is consistent with past research with sexually aggressive men (e.g., Hersh \& Gray-Little, 1998) and coercers (e.g., Koss \& Dinero, 1988). However, as this factor was no longer significant in either of the final models when other risk factor categories were included, it is possible that aggressive tendencies may predispose individuals to violence generally but result in sexual perpetration only when combined with other shared (e.g., rape myths) or unique (e.g., social potency, hostility toward women) risk factors for coercion or aggression. Last, an impaired capacity for experiencing genuine compassion and concern for others may play an important role in distinguishing men who engage in sexual perpetration from those who do not. The significance of these basic empathy deficits in the final sexual coercion model is somewhat surprising given the lack of overt victim distress that would be expected to accompany these tactics. However, it may be that reduced concern for, or ability to detect, a potential partner's feelings or attempts at resistance also removes a potential barrier to the use of continued pressure or manipulation. In contrast, the role of empathic deficits in sexual aggression is well established (e.g., Lisak \& Ivan, 1995; Covell \& Scalora, 2002; Fernandez \& Marshall, 2003) and addressed in many sex offender treatment programs (Marshall, 1999). The fact that empathic concern was significant in the first level of analyses but not in the final model for sexual aggression suggests that these empathic deficits may make it possible to engage in these behaviors, 
but that they may need to be activated by other risk characteristics (i.e., hostility toward women, carefree nonplanfulness) to result in these more severe acts.

In contrast to the above characteristics that seem to put men at risk for both sexual coercion and aggression, unique risk factors were also identified. These unique characteristics point to qualitative differences between those offenders who use only coercive strategies and those who have "crossed the line" to engage in more severe physical tactics. The final model of sexual coercion identified two predictors unique to these lower level offenders; these factors, assessed by specific subscales of the empathy and psychopathy measures, point to an important role for personality traits in the prediction of sexual coercion. Interestingly, each of these characteristics seems to provide the perpetrator with a set of "skills" or advantages that would likely enhance their ability to "successfully" engage in sexual coercion. For instance, on the fantasy subscale of the empathy measure, coercers demonstrated a greater ability to imagine and identify with the feelings of fictional characters. This ability could prove useful to coercers by allowing them to better anticipate women's reactions to their sexual advances and, consequently, develop and implement more effective coercive tactics (e.g., arguments, threats, deceit, etc.). Similarly, coercers' higher scores on the social potency aspect of psychopathy suggest an ability and willingness to manipulate others using verbal prowess and superficial charm, characteristics with direct relevance to the successful use of verbal tactics. Therefore, although most of the perpetrators had used sexually coercive tactics in the past, those who used only coercive tactics tended to share a constellation of personality traits that would likely make such tactics a viable option for obtaining intercourse with unwilling females, perhaps making the use of more violent physical tactics unnecessary.

In contrast, the final model of sexual aggression points to a cluster of traits assessed by the carefree nonplanfulness scale of the psychopathy scale as a primary unique predictor of physical tactics. Reflecting a tendency to act impulsively without considering potential consequences and a general disinterest in conforming to societal norms and mores, this factor may account, in part, for the willingness of these men to cross the line from inappropriate (e.g., coercive) to illegal (e.g., aggressive) sexual activities. In fact, assuming that some constellation of other risk factors is also present, a critical factor in predicting whether men will actually engage in sexual aggression may be their ability to clear a major psychological hurdle involving fear of being caught and punished, concern about social perceptions of rapists, and a desire to see oneself as a law-abiding member of society. Without overcoming these obstacles through a combination of impulsivity and indifference, these men may remain engaged in only consensual relationships or lower level coercive activities despite the presence of other risk factors. Other unique predictors, including hostility toward women, empathic concern, egocentricity, and emotional abuse history, were significant within their respective variable categories, but not in the final model of sexual aggression. It may be that a confluence of factors is more important to the prediction of sexual aggression than any one factor in isolation. Indeed, these results suggest that men who engage in sexually aggressive acts possess a unique combination of high-risk attitudes 
(i.e., hostility and anger toward women), personality traits (i.e., impulsivity and indifference to legal and societal norms, exaggerated self-importance), and experiences (i.e., childhood emotional abuse) that permit or encourage them to use physical tactics to achieve sexual contact without regard for consequences to themselves or harm to their female victims.

Finally, in the model that directly contrasted sexually coercive and aggressive men, the most important unique factor distinguishing sexual offenders who only coerce from those who only or also engage in sexual aggression was hostility toward women, with greater hostility reported by aggressive men. Thus, feelings of anger, suspicion, resentment, and vengeance toward women seem to represent a critical difference between those men who engage only in lower level offending and those who escalate to more violent and potentially harmful acts. These findings support the positions of some feminist authors (e.g., Brownmiller, 1975) that control and power over women may be an important component of rape, and also suggest that physical and emotional harm to the victim may be, at best, a consequence of sexual aggression that the offender is unconcerned with and, at worst, an actual motive for the behavior. It is notable that more than $90 \%$ of sexually aggressive men in this study had also engaged in sexually coercive behaviors. Thus, it makes sense that each of the factors included in this model (i.e., hostility toward women, generalized aggression, and emotional abuse) were also predictors in the sexual aggression model specifically. The presence of so many coercive men in the aggressive group may also explain the lower classification rates for sexual aggressors in this model. Although the correct classification rates were $70 \%$ for the overall model and $96.7 \%$ for sexual coercers, only $7.2 \%$ of sexual aggressors were classified correctly using this model. These results suggest that, despite being distinct from each other and consensual-only men on several key factors, coercers and aggressors may be more similar than they are different.

The current investigation has several limitations that should be considered. First, although the incarcerated sample was useful for obtaining a larger group of sexual aggressors, the nature of this sample may limit generalizability of the results. For instance, men in the "consensual-only" group had been convicted of at least one felony criminal offense and, thus, are not representative of consensual-only men in the general population. Second, the use of retrospective, self-report measures to assess sensitive information about participants' sexual offenses leaves room for intentional and unintentional misreporting and increases the potential for shared method variance (e.g., the possibility that the group differences identified simply reflect differences between those willing and unwilling to disclose sexual perpetration). For sexual aggression, however, self-reports were also supplemented with institutional records of sexual assault convictions - and because sexual coercion does not typically meet the threshold for a criminal offense, researchers must rely on self-report methods to assess these acts. Finally, the current study focused only on individual-level predictors of sexual violence. Expansion of these models to include additional risk factors, such as biological (e.g., Aromaki, Lindman, \& Eriksson, 2002) or situational (e.g., Abbey, Zawacki, \& Buck, 2005) variables, would likely improve the models' overall predictive power. 
Several findings from the current investigation point to an important behavioral relationship between sexual coercion and aggression that is worthy of further investigation. First, more similar than unique predictors of sexual coercion and aggression were identified here, suggesting that these forms of perpetration have a shared etiology. Similarly, the model of sexual perpetration, although significant, was relatively ineffective at distinguishing between sexually coercive and aggressive men, suggesting that these two offender groups may be more similar than they are different. Furthermore, more than $90 \%$ of sexually aggressive men also reported the use of sexually coercive tactics indicating that sexual aggression rarely occurs without prior or concurrent use of sexually coercive tactics. Taken together, these findings support the possibility that sexual aggressors may engage in lower level sexually coercive behaviors as a stepping stone to more severe acts, and that sexual coercion itself may be an effective indicator of heightened risk for sexual aggression. A longitudinal study that follows consensual-only and coercive-only men over a period of time to assess the relative likelihood of escalating to sexually aggressive tactics is needed to illuminate the temporal links between these two offense types. Either way, this study provides further evidence of important risk and etiological differences between physical and nonphysical forms of sexual perpetration, and highlights the need for additional research that examines these perpetrator groups independently.

A recent article by Mary Koss (2005) reflecting on the past 20 years of rape research suggests that existing sexual violence prevention programs are not as effective as originally hoped and that new approaches to prevention are needed. The present findings point to the importance of including coercion-specific material in sexual assault prevention programs. Specifically, the high frequency of sexual coercion found here and elsewhere (e.g., Koss et al., 1985; Lyndon et al., 2007; Struckman-Johnson et al., 2003) suggests that many men may not recognize these tactics as inappropriate or potentially harmful. This may be especially true in comparison with sexually aggressive tactics, which are socially and legally prohibited. Thus, incorporating strategies within existing prevention programs to change attitudes and social norms regarding the potential harm and problematic nature of sexually coercive tactics, specifically, may help reshape perceptions of these tactics as unacceptable. Second, given that nearly all men reporting the use force also reported the use of other manipulative tactics, focusing prevention efforts on men who report prior use of sexual coercion on a brief screening questionnaire may capture a large proportion of sexually aggressive men, as well as many of those at risk for escalating to the use of more severe tactics. The ability to direct limited prevention resources to a high-risk subgroup may increase the cost-effectiveness of these interventions. Third, this study is one of the first to identify specific predictive factors unique to sexual coercion. Although the results reveal that some shared risk factors like belief in rape myths and empathic deficits (standard components of many prevention and treatment programs) should be targets of intervention for both coercive and aggressive men, it might also be beneficial to consider factors unique to coercion when designing or implementing preventive interventions. For example, addressing the social potency dimension of psychopathy might be especially 
valuable in the prevention of sexual coercion. Even in the context of a group-based prevention program, the role of these characteristics in the perpetration of sexual coercion can be addressed. For instance, the use of certain "skills" (e.g., being "charming," persuasive, or a "good actor") could be reframed as helpful and acceptable in some social or professional situations, but inappropriate and "off limits" when used to take advantage of or convince an unwilling sexual partner. Although much work is still needed to translate such findings into the development of new prevention strategies, it is clear that ongoing efforts to illuminate the etiology of offending, including the results of the present study, are needed to inform and improve effective approaches to the primary prevention of sexual violence.

\section{Authors' Note}

Sarah DeGue is now with the Division of Violence Prevention at the Centers for Disease Control and Prevention in Atlanta, GA. Points of view are those of the authors and do not necessarily represent the positions of the National Institute of Mental Health or the Centers for Disease Control and Prevention.

\section{Acknowledgments}

We would like to thank Stephanie Bruhn, Lorraine Cuadra, and our undergraduate research assistants for their assistance with data collection.

\section{Declaration of Conflicting Interests}

The author(s) declared no conflicts of interest with respect to the authorship and/or publication of this article.

\section{Funding}

The author(s) disclosed that they received the following support for their research and/or authorship of this article:

The present study was supported by a training grant from the National Institutes of Mental Health (F31 MH071081-0A1; Principal Investigator, Sarah DeGue) under the supervision of David DiLillo, and a University of Nebraska-Lincoln Maude Hammond Fling Fellowship awarded to Sarah DeGue.

\section{References}

Abbey, A., McAuslan, P., Zawacki, T., Clinton, A. M., \& Buck, P. O. (2001). Attitudinal, experiential, and situational predictors of sexual assault perpetration. Journal of Interpersonal Violence, 16, 784-807.

Abbey, A., Zawacki, T., \& Buck, P. O. (2005). The effects of past sexual assault perpetration and alcohol consumption on men's reactions to women's mixed signals. Journal of Social and Clinical Psychology, 24, 129-155.

Aberle, C. \& Littlefield, R. (2001). Family functioning and sexual aggression in a sample of college men. Journal of Interpersonal Violence, 16, 565 -579.

Adams-Curtis, L. E. \& Forbes, G. B. (2004). College women's experiences of sexual coercion. Trauma, Violence, \& Abuse, 5, 91-122. 
Allison, P. D. (1999). Logistic regression using the SAS system: Theory and application. Cary, NC: SAS Institute.

Aromaki, A. S., Lindman, R. E., \& Eriksson, C. J. (2002). Testosterone, sexuality, and antisocial personality traits in rapists and child molesters. Psychiatry Research, 110, 239-247.

Basile, K. C., \& Saltzman L. E. (2002). Sexual violence surveillance: Uniform definitions and recommended data elements (Version 1.0). Atlanta, GA: Centers for Disease Control and Prevention, National Center for Injury Prevention and Control.

Bernat, J. A., Calhoun, K. S., \& Adams, H. E. (1999). Sexually aggressive and nonaggressive men: Sexual arousal and judgments in response to acquaintance rape and consensual analogues. Journal of Abnormal Psychology, 108, 662-73.

Bronbrenbrenner, U. (1979). Ecology of human development: Experiments by nature and design. Cambridge, MA: Harvard University Press.

Brown, A. L., Testa, M., \& Messman-Moore, T. L. (2009). Psychological consequences of sexual victimization resulting from force, incapacitation, and verbal coercion. Violence Against Women, 15, 898-919.

Brownmiller, S. (1975). Against our will: Men, women, and rape. New York, NY: Simon \& Schuster.

Bumby, K. M. (1996). Assessing the cognitive distortions of child molesters and rapists: Development and validation of the MOLEST and RAPE scales. Sexual Abuse: A Journal of Research and Treatment, 8, 37-54.

Burt, M. (1980). Cultural myths and supports for rape. Journal of Personality and Social Psychology, 38, 217-230.

Buss, A. H., \& Perry, M. (1992). The aggression questionnaire. Journal of Personality and Social Psychology, 63, 452-459.

Byers, E., \& Eno, R. (1991). Predicting men's sexual coercion and aggression from attitudes, dating history, and sexual response. Journal of Psychology and Human Sexuality, 4, 55-69.

Calhoun, K. S., Bernat, J. A., Clum, G. A., \& Frame, C. L. (1997). Sexual coercion and attraction to sexual aggression in a community sample of young men. Journal of Interpersonal Violence, 12, 392-406.

Campbell, R., \& Wasco, S. M. (2005). Understanding rape and sexual assault: 20 years of progress and future directions. Journal of Interpersonal Violence, 20, 127-131.

Check, J. V. P., Malamuth, N. M., Elias, B., \& Barton, S. (1985). On hostile ground. Psychology Today, April, 56-61.

Covell, C. N., \& Scalora, M. J. (2002). Empathic deficits in sexual offenders: An integration of affective, social,and cognitive constructs. Aggression and Violent Behavior, 7, 251-270.

Craig, M., Kalichman, S., \& Follingstad, D. (1989). Verbal coercive sexual behavior among college students. Archives of Sexual Behavior, 18, 421-434.

Davis, M. H. (1980). A multidimensional approach to individual differences in empathy. JSAS Catalog of Selected Documents in Psychology, 10, 85.

DeGue, S., \& DiLillo, D. (2004). Understanding perpetrators of sexual coercion: Characteristics of those who cross the line. Violence and Victims, 19, 673-688.

DeGue, S., \& DiLillo, D. (2005). "You would if you loved me": Toward an improved conceptual and etiological understanding of male sexual coercion. Aggression and Violent Behavior, $10,513-532$. 
Dhawan, S., \& Marshall, W. L. (1996). Sexual abuse histories of offenders. Sexual Abuse: A Journal of Research and Treatment, 8, 7-15.

Fernandez, Y. M., \& Marshall, W. L. (2003). Victim empathy, social self-esteem, and psychology in rapists. Sexual Abuse: A Journal of Research and Treatment, 15, 11-26.

Fink, L., Bernstein, D., Handelsman, L., Foote, J., \& Lovejoy, M. (1995). Initial reliability and validity of the Childhood Trauma Interview: A new multidimensional measure of childhood interpersonal trauma. American Journal of Psychiatry, 152, 1329-1335.

Hare, R. (1991). The Hare Psychopathy Checklist-Revised. Toronto, Ontario, Canada: MultiHealth Systems.

Hersh, K., \& Gray-Little, B. (1998). Psychopathic traits and attitudes associated with selfreported sexual aggression in college men. Journal of Interpersonal Violence, 13, 456-471.

Kilpatrick, D. G., Resnick, H. S., Ruggiero, K. J., Conoscenti, L. M., \& McCauley, J. (2007, June). Drug-facilitated, incapacitated, and forcible rape: A national study. Final report submitted to the National Institute of Justice, Grant No. 2005-WG-BX-0006.

Knight, R., \& Sims-Knight, J. (2009, September). Using rapist risk factors to set an agenda for rape prevention. Harrisburg, PA: VAWnet, a project of the National Resource Center on Domestic Violence/Pennsylvania Coalition Against Domestic Violence. Retrieved from http://www.vawnet.org.

Koss, M. P. (2005). Empirically enhanced reflections on 20 years of rape research. Journal of Interpersonal Violence, 20, 100-107.

Koss, M. P., \& Dinero T. E. (1988). Predictors of sexual aggression among a national sample of male college students. Annals of the New York Academy of Sciences, 528, 133-147).

Koss, M. P., \& Gidycz, C. A. (1985). Sexual experiences survey: Reliability and validity. Journal of Consulting and Clinical Psychology, 53, 422-423.

Koss, M. P., Gidycz, C. A., \& Wisniewski, N. (1987). The scope of rape: Incidence and prevalence of sexual victimization in a national sample of higher education students. Journal of Consulting and Clinical Psychology, 55, 162-170.

Koss, M. P., Leonard, K. E., Beezley, D. A., \& Oros, C. J. (1985). Nonstranger sexual aggression: A discriminant analysis of the psychological characteristics of undetected offenders. Sex Roles, 12, 981-992.

Koss, M. P., \& Oros, C. J. (1982). Sexual experiences survey: A research instrument investigating sexual aggression and victimization. Journal of Consulting and Clinical Psychology, 50, 455-457.

Kosson, D. S., \& Kelly, J. C. (1997). Psychopathy-related traits predict self-reported sexual aggression among college men. Journal of Interpersonal Violence, 12, 241-258.

Lilienfeld, S. O. (1990). Development and preliminary validation of a self-report measure of psychopathic personality (Unpublished doctoral dissertation). University of Minnesota, Minneapolis.

Lilienfeld, S. O., \& Andrews, B. P. (1996). Development and preliminary validation of a selfreport measure of psychopathic personality traits in noncriminal populations. Journal of Personality Assessment, 66, 488-524.

Lindsey, R. E., Carlozzi, A. F., \& Eells, G. T. (2001). Differences in the dispositional empathy of juvenile sex offenders, non-sex-offending delinquent juveniles, and nondelinquent juveniles. Journal of Interpersonal Violence, 16, 510-522. 
Lisak, D., \& Ivan, C. (1995). Deficits in intimacy and empathy in sexually aggressive men. Journal of Interpersonal Violence, 10, 296-308.

Lisak, D., \& Roth, S. (1988). Motivational factors in nonincarcerated sexually aggressive men. Journal of Personality and Social Psychology, 55, 795-802.

Livingston, J. A., Buddie, A. M., Testa, M., \& VanZile-Tamsen, C. (2004). The role of sexual precedence in verbal sexual coercion. Psychology of Women Quarterly, 28, 287-297.

Lyndon, A. E., White, J. W., \& Kadlec, K. M. (2007). Manipulation and force as sexual coercion tactics: Conceptual and empirical differences. Aggressive Behavior, 33, 291-303.

Malamuth, N. M., Heavey, C. L., \& Linz, D. (1993). Predicting men's antisocial behavior against women: The interaction model of sexual aggression. In G. N. Hall, J. Hirschman, J. Graham, \& M. Zaragoza (Eds.), Sexual aggression: Issues in etiology, assessment and treatment (pp. 63-97). Washington, DC: Hemisphere.

Malamuth, N. M., Linz, D., Heavey, C. L., Barnes, G., \& Acker, M. (1995). Using the confluence model of sexual aggression to predict men's conflict with women: A 10-year follow-up study. Journal of Personality and Social Psychology, 69, 353-369.

Malamuth, N. M., Sockloskie, R. J., Koss, M. P., \& Tanaka, J. S. (1991). Characteristics of aggressors against women: Testing a model using a national sample of college students. Journal of Consulting and Clinical Psychology, 59, 670-681.

Marshall, W. L. (1999). Current status of North American assessment and treatment programs for sexual offenders. Journal of Interpersonal Violence, 14, 221-239.

Mosher, D. L., \& Anderson, R. D. (1986). Macho personality, sexual aggression, and reactions to guided imagery of realistic rape. Journal of Research in Personality, 20, 77-94.

Muehlenhard, C., \& Falcon, P. (1990). Men's heterosocial skill and attitudes toward women as predictors of verbal sexual coercion and forceful rape. Sex Roles, 23, 241-259.

Pulos, S., Elison, J., \& Lennon, R. (2004). The hierarchical structure of the Interpersonal Reactivity Index. Social Behavior and Personality: An International Journal, 32, 355-359.

Rapaport, K., \& Burkhart, B. R. (1984). Personality and attitudinal characteristics of sexually coercive college males. Journal of Abnormal Psychology, 93, 216-221.

Senn, C., Desmarais, S., Verberg, N., \& Wood, E. (2000). Predicting coercive sexual behavior across the lifespan in a random sample of Canadian men. Journal of Social and Personal Relationships, 17, 95-113.

Simons, D., Wurtele, S. K., \& Heil, P. (2002). Childhood victimization and lack of empathy as predictors of sexual offending against women and children. Journal of Interpersonal Violence, 17, 1291-1307.

Struckman-Johnson, C., Struckman-Johnson, D., \& Anderson, P. B. (2003). Tactics of sexual coercion: When men and women won't take no for an answer. Journal of Sex Research, 40, 76-86.

Testa, M., \& Derman, K. H. (1999). The differential correlates of sexual coercion and rape. Journal of Interpersonal Violence, 14, 548-561.

Tyler, K. A., Hoyt, D. R., \& Whitbeck, L. B. (1998). Coercive sexual strategies. Violence and Victims, 13, 47-61.

Zweig, J. M., Barber, B., \& Eccles, J. (1997). Sexual coercion and well-being in adulthood: Comparisons by gender and college status. Journal of Interpersonal Violence, 12, 291-308. 